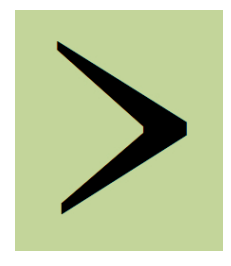

\author{
Papers in Historical Phonology \\ http://journals.ed.ac.uk/pihph \\ ISSN 2399-6714 \\ Volume $1,285-315$ \\ DOI: $10.2218 /$ pihph.1.2016.1704
}

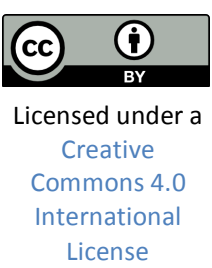

\title{
From phonetic enhancement to phonological underspecification: hybrid voicing contrast in European Portuguese
}

\author{
MiCHAEL RAMSAMMY \\ University of Edinburgh \\ PATRYCJA STRYCHARCZUK \\ University of Manchester
}

\begin{abstract}
Laryngeal contrast in European Portuguese has typically been described in the phonological literature in terms of an opposition between [+voice] and [-voice]. However, a number of phonetic studies have revealed that lenis fricatives in European Portuguese tend not to exhibit consistent, robust voicing. Focusing on the sibilant system, this paper has a threefold goal. Firstly, we present results of a phonetic study designed to test the realisation of sibilants both in contrast and neutralisation contexts. Secondly, we propose a reanalysis of synchronic laryngeal contrast couched in the laryngeal realist tradition. Our claim is that an analysis in which fortis fricatives are specified for [spread glottis] makes more accurate phonetic predictions than alternative approaches. Our analysis entails the secondary claim that European Portuguese exemplifies what we term a hybrid voicing system: whilst [spread glottis] is the key contrast feature for the fricative series, the stop series can be best handled by assuming that lenis stops are specified for [voice]. Thirdly, we develop a possible diachronic scenario for how such a hybrid system may have emerged diachronically as the result of phonological changes in the history Portuguese.
\end{abstract}

\section{Introduction}

This paper addresses questions concerning the phonetic properties, phonological status and diachronic development of sibilant fricatives in European Portuguese (EP hereafter). Traditional phonological descriptions typically state that the central standard dialect of EP (as spoken in and around the city of Lisbon) displays a four-way sibilant contrast based on voicing and place-of-articulation features. As shown in (1) below, voiceless alveolar /s/ contrasts with a voiced counterpart, 
/z/, in onset position. These sibilants, in turn, contrast with voiceless and voiced post-alveolar counterparts, $/ \int, 3 /$, in the same environments.

\begin{tabular}{l|llllll}
\hline & \multicolumn{2}{|l}{ Alveolar } & \multicolumn{4}{l}{ Post-alveolar } \\
\hline Voiceless & caça & {$[\mathrm{ka} . \mathrm{se}]$} & 'hunt' & caixa & {$[\mathrm{kej} . \mathrm{fe}]$} & 'box' \\
Voiced & casa & {$[\mathrm{ka} . \mathrm{ze}]$} & 'house' & queijo & {$[\mathrm{kej} .3 \mathrm{u}]$} & 'cheese' \\
\hline
\end{tabular}

Outside of onset position, this four-way contrast is neutralised. In word-medial pre-consonantal contexts, sibilants have post-alveolar place and assimilate in voicing to following onsets (see examples in 2). In word-final pre-pausal contexts (3a), neutralisation yields [ $]$ ]. Place and voicing contrasts are also suspended in word-final pre-vocalic environments (3b), but here the output of neutralisation is [z].

(2) Pre-consonantal sibilant neutralisation

\begin{tabular}{|c|c|c|c|c|c|}
\hline (a) ne & tralisatic & to $\left[\int\right]$ & (b) neut & alisation $\mathrm{t}$ & [3] \\
\hline caspa & [ka\}.pe] & 'dandruff' & esboço & [i3.bo.su] & 'sketch' \\
\hline casta & [kaf.te] & 'caste' & desdem & [dì3.dẽỹ] & 'distain' \\
\hline casca & [kaf.ke] & 'shell' & rasga & [ваз.ge] & 'tear.3SG' \\
\hline
\end{tabular}

(3) Word-final sibilant neutralisation

\begin{tabular}{llll}
\hline (a) pre-pausal contexts & (b) prevocalic contexts & \\
rapaz [ве.pa]] II boy & rapaz alto [ве.pa.zał.tu] & 'tall boy' \\
\hline
\end{tabular}

There have been various approaches to analysing these patterns in the phonological literature on Portuguese. Mateus \& d'Andrade (2000) base their analysis on the assumption of radical underspecification at the lexical level. In this model, /s/ is unmarked and specified only as [+cont]. This contrasts with / $\mathrm{z} /$ which is [+cont, +voice]. The postalveolar sibilants, $/ \int, 3 /$, are [+cont, -ant] and [+cont, +voice, -ant], respectively. Missing feature values are supplied either by featurespread-i.e. in the assimilation environments shown in (2a-b) - or by default feature insertion. In non-assimilation environments, underspecified $/ s_{\varnothing} /$ is supplied with [coronal, +ant] place features syllable initially, whereas syllable final $/ \mathbf{s}_{\varnothing} /$ acquires [coronal, $-\mathrm{ant}$ ] by default, thereby generating pattern (3a). Laryngeal features (i.e. [voice]) are then supplied to laryngeally underspecified /s, $\int /$ by feature 
filling processes, such that all surface representations are argued to be fully specified. ${ }^{1}$

Similar to Mateus \& d'Andrade (2000), Cristófaro Silva's (1998: 157-158) analysis of word-final neutralisation is based on underspecification. With reference to Brazilian dialects, Cristófaro Silva claims that the four-way sibilant contrast that occurs in onset position is neutralised in coda position to an archiphoneme, $/ \mathrm{S} /$, that lacks place and voicing features. Resyllabification of syllable-final /S/ in pre-vocalic phrasal contexts is argued to be the cause of sibilants in examples like (3b) showing voicing and having alveolar (i.e. not post-alveolar) place. ${ }^{2}$ However, like Mateus \& d'Andrade, Cristófaro Silva does not elaborate on whether this process is best analysed as feature spread from surrounding vowels or addition of default features.

Herslund (1986: 509-513) takes a different stance on word-final sibilant neutralisation and assumes that [f] in (3a) and [z] in (3b) are surface reflexes of underlying /z/. Whilst this analysis is not formalised in terms of feature-change operations, they key claim is that pre-pausal /z/ undergoes a devoicing and palatalisation process that targets codas. In cases like ( $3 b)$ neutralisation fails to apply because pre-vocalic resyllabification across a word boundary removes word-final /z/ from coda position.

In addition to phonological analyses, a number of phonetic studies have examined voicing contrasts in EP. For example, Lousada, Jesus \& Hall (2010) tested the realisation of EP stops in different phonological contexts. These authors report that lenis stops /b, d, g/ show clear acoustic evidence of pre-voicing in word-initial and word-medial environments, ${ }^{3}$ and that lenis stops are distinguishable from fortis stops across a number of phonetic parameters (including VOT, closure duration and duration of surrounding vowels). Nevertheless, instances of devoicing were also observed. As reported for other languages, this

\footnotetext{
1 Mateus \& d'Andrade (2000) do not present an analysis of the voicing of word-final pre-vocalic /s/ (3b) in their discussion of connected speech processes (144ff.). It is unclear whether they view this as the result of feature spread from surrounding vowels, or whether they would assume some type of default feature epenthesis. However, Azevedo (2005: 45) states specifically that pattern (3b) is the result of spread of voicing from the following, word-initial vowel.

2 Some Brazilian dialects do not exhibit post-alveolar sibilants in coda position. Such varieties instead display only voicing assimilation (i.e. without palatalisation) in preconsonantal environments (e.g. casca [kas.ke], rasga [xaz.ge]) and default to [s] prepausally (e.g. rapaz [xepas]). Both European and Brazilian dialects neutralise sibilant contrasts to [z] in word-final pre-vocalic contexts (although Hammarström 1953: 173 reports use of [3] in this environment in Algarve dialects).

3 VOT measurements averaged over six speakers and three stops (i.e. /b, d, g/) were -88 msecs for word-initial stops and -59 msecs for word-medial stops.
} 
was found to correlate with place of articulation: $[\mathrm{b}]$ is more resistant to devoicing than [d]; and [d], in turn, showed less devoicing than [g]. Devoicing was also more common word-finally than in initial or medial environments.

In contrast to the relatively high levels of voicing found by Lousada et al. in stops, Jesus \& Shadle (2002) found strong evidence of devoicing in EP lenis fricatives. Acoustic measurements extracted from [v, z, 3]realisations in three word positions reveal devoicing in approximately $50 \%$ of tokens on average. Devoicing of lenis fricatives is more common in word-final position than word-initially or word-medially; and generally, high levels of inter- and intra-speaker variability were observed. A similar study carried out by Pape \& Jesus (2011) also found relatively high levels of devoicing in EP lenis fricatives, and these authors report extensive variability between speakers. ${ }^{4}$

However, airflow and laryngographic (EGG) data reported in Pinho, Jesus \& Barney (2012) provide a somewhat different picture with regard to fricative voicing. Whereas Jesus \& Shadle (2002) report an average of $50 \%$ cases of devoicing in lenis fricatives based on acoustic measurements, Pinho et al. (2012: 629) found some evidence of mild voicing in $93 \%$ of lenis fricatives (averaged over measurements extracted from [V, z, 3] in three word positions from four speakers). On the basis of this result, the authors conclude that voicing in EP lenis fricatives is consistent to some degree, but it is often too weak to be reliably measureable acoustically. ${ }^{5}$

In sum, the literature on obstruent voicing in EP presents two contentions. Existing phonological analyses have not reached a consensus about the status of laryngeal contrast or the operation of laryngeal neutralisation in EP. Both Mateus \& d'Andrade (2000) and Cristófaro Silva (1998) develop analyses of sibilant neutralisation in which underspecification plays a role; yet what the predictions of these analyses are for speech production-especially under Mateus \& d'Andrade's approach assuming full surface specification-remains to be addressed. Additionally, whilst instrumental studies have shed light onto the acoustic and aerodynamic properties of EP obstruents, the

\footnotetext{
4 In the most extreme case, one speaker devoiced $14 \%$ of tokens of [3], whereas another speaker reading the same stimuli produced $83 \%$ of tokens of [3] with devoicing.

5 This observation also has important consequences for perception. If voicing of EP lenis fricatives is so weak that it cannot be reliably measured using acoustic techniques, then it is unlikely that weak voicing is perceptible in natural speakinghearing conditions. This raises the question of how a phenomenon like weak voicing could potentially be acquired by children.
} 
implications of such experimental results for the phonology of the language have not been given full attention.

The overarching aim of this article is therefore to unify experimental work on sibilant fricatives in EP with a phonological account that makes adequate predictions about their synchronic phonetic realisation and diachronic development. In $\S 2$ below, we present results from a new phonetic study designed to test the realisation of sibilants in contrast and neutralisation environments. Due to space limitations, we focus on the realisation of sibilants in prevocalic contexts in this paper: it is the results from this part of the experimental study that have the most important implications for questions relating to voicing contrast. In agreement with previous work, our data reveal that voicing of lenis sibilants is highly variable. We also observe differences in the realisation of voicing in /z, 3/ for female and male speakers. Analysis of these data lead us ultimately to conclude that voicing in EP sibilants can best be characterised as passive, rather than active: i.e. voicing is mainly coarticulatory, rather than being produced by a distinct voicing gesture (Jansen 2004).

In $\S 3$, we consider the implications of these phonetic results for developing a synchronic analysis of laryngeal contrast in EP. Our approach is based in laryngeal realism (Iverson \& Salmons 1995, 2003, 2006; Jessen \& Ringen 2002; Beckman, Jessen \& Ringen 2006, 2009, 2013; Honeybone 2005). As the name implies, the goal of developing phonological analyses of laryngeal contrasts that most closely reflect the phonetic realisation of voicing contrasts in speech is one of the core concerns of this research tradition. Thus, this phonetically-informed approach aims to shape theoretical accounts around phonetic reality by explicitly relating theoretical claims to testable phonetic predictions.

In keeping with this goal, our interpretation of the phonetic data leads us to propose, firstly, that fortis sibilants in EP are specified for [spread glottis]. Secondly, we argue that lenis sibilants are phonetically underspecified for laryngeal features (in the sense of Keating 1988): in other words, they are not contrastively specified as [(+)voice]. Thirdly, we argue that laryngeal contrast in the fricative series does not parallel contrasts in the stop series. Instead, we propose that fortis stops are underspecified for laryngeal features, whereas lenis stops are contrastively specified for [voice]. The essence of our reanalysis, therefore, is that EP exemplifies a hybrid voicing system: fortis lenis contrasts are based on laryngeal underspecification vs [voice] for stops, but on [spread glottis] vs underspecification for fricatives. Whilst this analysis differs significantly from existing phonological work on EP, we show that our approach is a better fit to currently available data on EP. Typologically, our analysis also situates EP in a different position from 
other 'true voice' Romance languages. In this sense, recognising the hybrid nature of EP's laryngeal contrast system provides an explicit theoretical link to Pape \& Jesus's (2011: 1569) observation that, regarding fricative voicing, 'EP is more similar to a Germanic language than to other Romance languages' (see also Pape \& Jesus 2015).

As well as providing a good fit with currently available phonetic data, our proposals about laryngeal contrast in present-day EP must also be evaluated from a diachronic perspective. Accordingly, $\S 4$ considers the historical development of the sibilant system of EP. Whereas Latin possessed a single sibilant phoneme, /s/, we illustrate a complex set of phonological changes that led to the emergence of multiple sibilant phonemes in the history of Portuguese. These changes have implications for the laryngeal phonology of the language. $§ 5$ considers how the hybrid voicing system that we propose for presentday EP may have developed diachronically. We argue that a crosslinguistic preference for voiceless fricatives (Vaux 1998) is the driving force behind the diachronic restructuring of laryngeal contrasts in the language. Thus, the emergence and lexicalisation of a pattern of [sg]specification on fortis fricatives (Iverson \& Salmons 2003) ultimately favours the elimination of [voice] as a contrast feature in fricatives. The cumulative outcome of these phonological changes in EP is a hybrid system of voicing contrast in which both [voice] and [spread glottis] play a role. $\S 6$ concludes the paper.

\section{Phonetic experiment}

\subsection{Experimental design and setup}

In order to gain a clearer understanding of the synchronic sibilant system in EP, we conducted an experiment designed to test the realisation of sibilants in the following phonological environments:

- word-medial position.

- word-final pre-vocalic position.

- word-final pre-pausal position.

- word-medial pre-consonantal position.

- word-final pre-consonantal position.

Participants read a series of stimulus sentences in which target words were embedded in the carrier sentence Diga __ outra vez ('Say __ again'). The set of target words used to test the realisation of pre-vocalic sibilants are listed in Figure 1 below. The stimulus set comprised an equal number of target sentences and distracter sentences. Stimuli were presented on a tablet computer in a fully randomised order using the PsychoPy (Peirce 2007) software package. 
Audio data were recorded using a Marantz PMD661 digital recorder $(44.1 \mathrm{kHz}$ sampling rate) and a Shure SM10A head-mounted microphone. The results presented in $\$ 2$ come from a convenience sample of 10 speakers ( 5 female and 5 male, mean age $=32$ ), all of whom were recruited through the Phonetics Laboratory at the University of Lisbon. All are speakers of the central standard dialect of EP. Recordings took place in the Phonetics Laboratory at the University of Lisbon and participants were paid $€ 10$ for taking part.

\begin{tabular}{|c|c|c|c|c|c|c|}
\hline \multicolumn{7}{|c|}{ Word-medial pre-vocalic: } \\
\hline & \multicolumn{3}{|c|}{ Post-tonic sibilants } & \multicolumn{3}{|c|}{ Pre-tonic sibilants } \\
\hline \multirow{2}{*}{ fortis } & caça & [káse] & 'hunt' (N) & caçar & [kesár] & 'hunt' (v) \\
\hline & caixa & [kéj]e] & 'box' & achar & [efár] & 'believe' \\
\hline \multirow{2}{*}{ lenis } & casa & [káze] & 'house' & casal & [kezáł] & 'couple' \\
\hline & queijo & [kéjzu] & 'cheese' & beijar & [bejzár] & 'kiss' \\
\hline \multicolumn{7}{|c|}{ Word-final pre-vocalic: } \\
\hline & \multicolumn{2}{|c|}{$\begin{array}{l}\text { ananás alpino } \\
\text { rapaz alto }\end{array}$} & \multicolumn{2}{|c|}{$\begin{array}{l}\text { [enenázałpínu] } \\
\text { [веpázáłtu] }\end{array}$} & \multicolumn{2}{|c|}{$\begin{array}{l}\text { 'alpine pineapple' } \\
\text { 'tall boy' }\end{array}$} \\
\hline
\end{tabular}

Figure 1: Test items used to test the realisation of pre-vocalic sibilants. Transcriptions are broad idealisations of expected realisations based on the existing research on EP cited in $§ 1$.

\section{Analysis}

Sibilant realisations were segmented manually in Praat (Boersma \& Weenink 1992-2016): see Ramsammy \& Strycharczuk (in preparation) for details. Following segmentation, measurements for six phonetic parameters (cf. Strycharczuk 2012) were extracted automatically by script, namely (i) voicing ratio, (ii) sibilant duration, (iii) mean centre of gravity, (iv) mean intensity, (v) mean intensity in lower spectral band $(0-500 \mathrm{~Hz})$, and (vi) mean intensity in upper spectral band $(500 \mathrm{~Hz}-$ $10 \mathrm{kHz}$ ). Statistical analysis using recursive partitioning was carried out in R (R Core Team 2016) equipped with the party package (Hothorn et al. 2015; see also Tagliamonte \& Baayen 2012, Plug \& Carter 2013, Strycharczuk et al. 2014).

\subsection{Results}

This section presents a summary of the phonetic results. Due to space limitations, we focus exclusively on analysis of voicing ratio ( $\$ 2.3 .1$ ) and sibilant duration (§2.3.2) in pre-vocalic sibilants. 
(a)
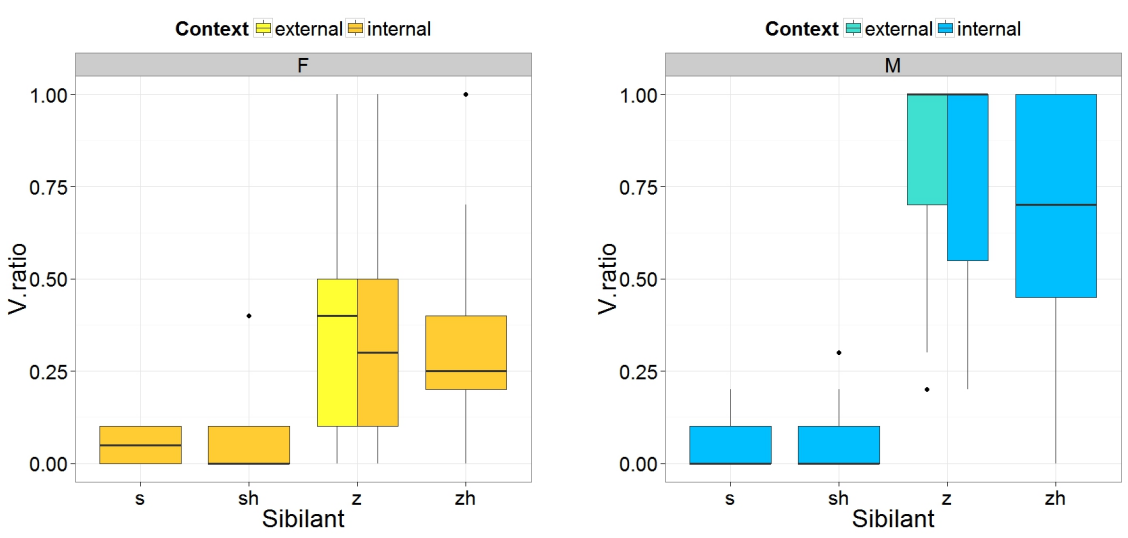

(b)
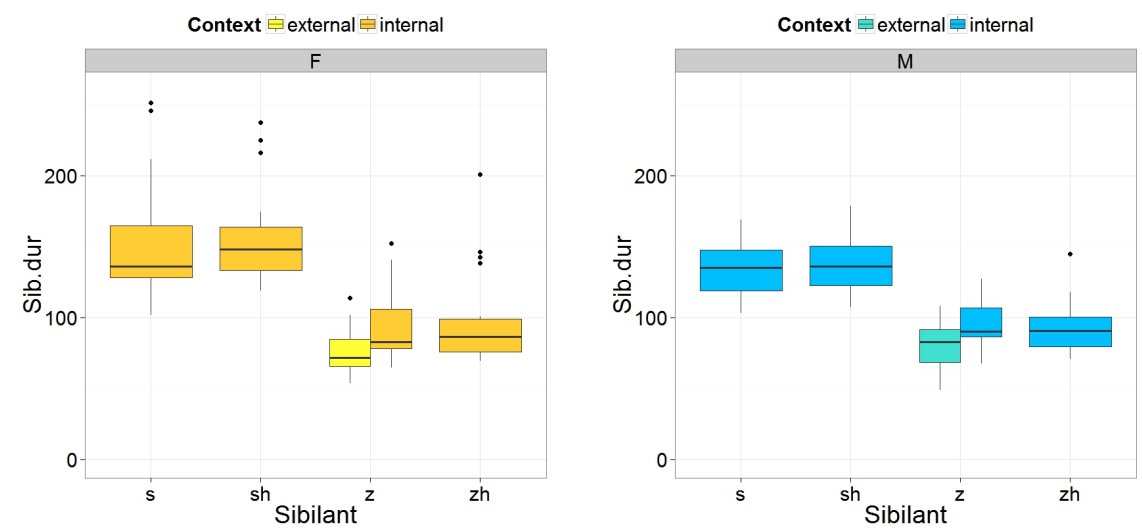

Figure 2: Boxplots of measurements of (a) voicing ratio and (b) sibilant duration (msecs), separated by speaker sex (females: left column, males: right column). Measurements are grouped as follows: $s=$ fortis alveolar sibilant, $s h=$ fortis post-alveolar sibilant, $z=$ lenis alveolar sibilant, $z h=$ lenis post-alveolar sibilant.

\subsubsection{Voicing ratio}

Figure 2 shows (a) voicing ratio measurements and (b) sibilant duration measurements extracted from pre-vocalic sibilant realisations. With regard to voicing ratio, observe that results from male speakers appear to be largely consistent with previous phonological descriptions of EP. Realisations of the fortis sibilants, /s/ and $/ \mathrm{J} /$, display floor-level values for voicing ratio, indicating the absence of any vocal fold vibration, except during transitional phases between the sibilant and the preceding vowel. By contrast, realisations of lenis /z/ and /3/ display much higher levels of voicing. Note that word-medial and wordfinal pre-vocalic /z/ displays a voicing ratio of 1 (i.e. $100 \%$ voicing) in a fairly high number of cases. Voicing of post-alveolar /3/ is marginally 
less robust with a median voicing ratio of approximately 0.7 (i.e. $70 \%$ voicing). In contrast to the relatively stable voicelessness of fortis sibilant realisations, observe furthermore that voicing in both lenis sibilants is much more variable, spanning a range of between $50 \%$ and $100 \%$ voicing for male speakers.

Realisations of fortis sibilants produced by female speakers show great similarity to those produced by male speakers: the near floorlevel voicing ratio values shown in Figure 2(a) confirm that female speakers consistently produced /s/ and / $/$ / without voicing. However, Figure 2(a) also shows that lenis sibilants produced by female speakers have quite a different realisation from those produced by male speakers. Observe here that voicing ratio values extracted tokens of $/ \mathrm{z} /$ and /3/ produced by female speakers typically show less than $50 \%$ voicing. This contrasts to the male speakers: recall that voicing of $/ \mathrm{z} /$ and $/ 3$ / ranges from $50 \%$ to $100 \%$ for males.

Despite the clear difference in the amount of voicing in lenis sibilants produced by female and male speakers, note that realisations of $/ z /$ and /3/ in both sex groups are characterised by high variability in voicing levels. Whilst all speakers in the experiment consistently produced fortis sibilants without voicing, the realisation of lenis sibilants is much more unstable with respect to measurements of voicing ratio, both within sex groups and across sex groups.

Statistical testing carried out on the data shown in Figure 2(a) using recursive partitioning confirms that there is a significant effect $(p<.001)$ of phonological category (i.e. fortis vs lenis) on voicing ratio values (see Figure 3). This supports the view that, with respect to voicing, the phonetic production of $/ \mathrm{s}, \mathrm{J} /$ is significantly different from /z, 3/ for all speakers. Furthermore, voicing ratio values in lenis sibilants produced by male speakers are also significantly higher $(p=0.005)$ than in lenis sibilants produced by female speakers. This result confirms that, whilst [s] and [S] have similar phonetic characteristics across speakers, realisations of /z/ and /3/ produced by men have significantly more voicing than realisations of $/ \mathrm{z} /$ and $/ 3 /$ produced by females. Finally, comparisons of word-medial /z/realisations (e.g. as in casa) with word-final pre-vocalic /z/-realisations (e.g. as in rapaz alto) do not reach significance $(p>.05)$ for either sex group. 


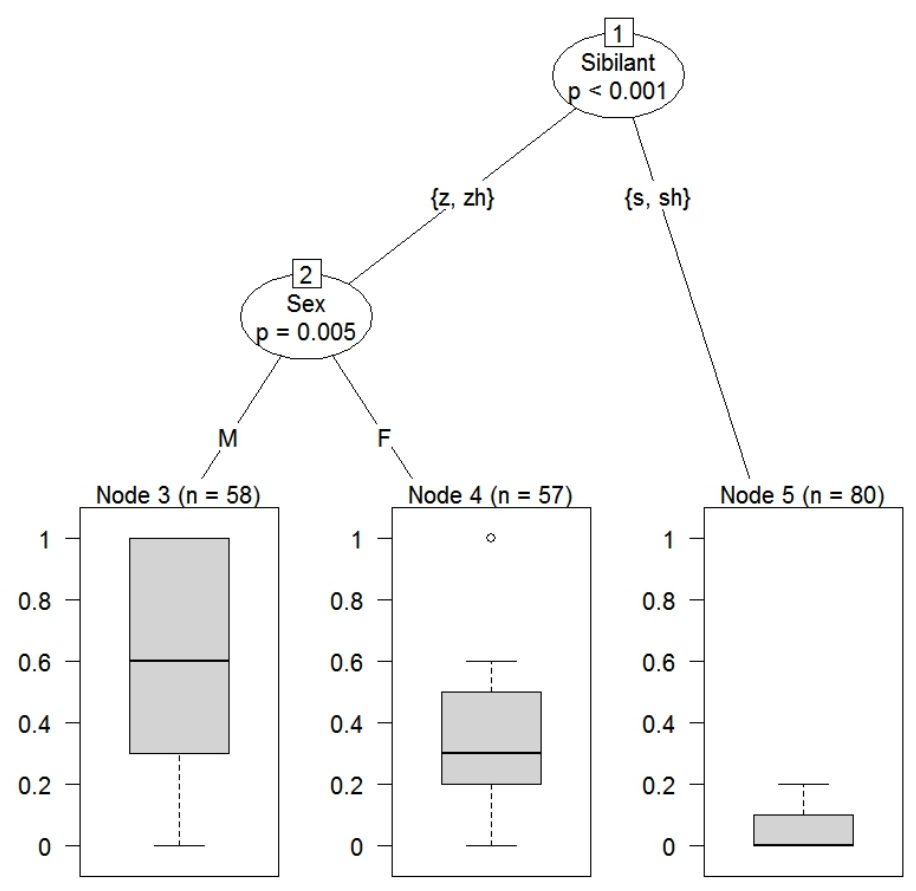

Figure 3: Conditional inference tree for voicing ratio measurements.

\subsubsection{Sibilant duration}

In addition to the fact that voicing ratio values are significantly different in fortis vs lenis sibilants for both sex groups, observe in Figure 2(b) that /s, J/ and /z, 3/ also differ with respect to duration. For both female and male speakers, duration values extracted from fortis sibilants typically approach c. 150 msecs. Lenis sibilants, by contrast, are shorter: duration values shown in Figure 2(b) for /z/ and /3/ cluster around c. 90 msecs, both for males and females. 


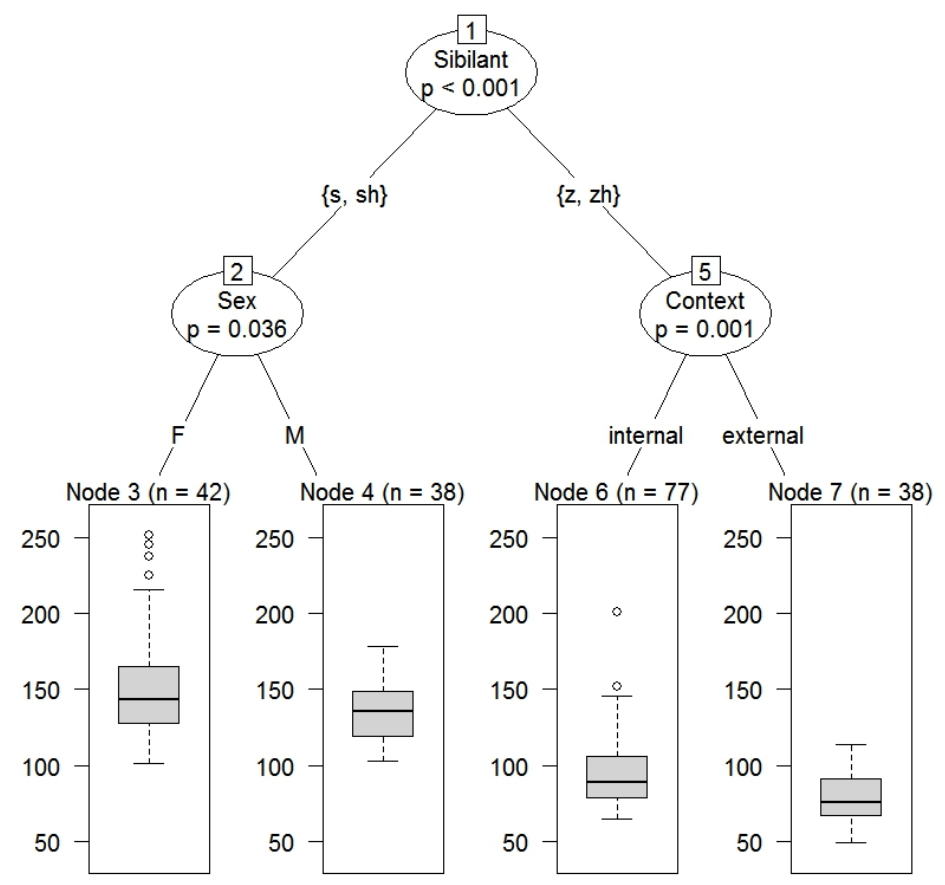

Figure 4: Conditional inference tree for sibilant duration measurements.

Statistical analysis of these data confirms that there is a robust effect of phonological category on duration values: fortis sibilants are significantly longer than lenis sibilants $(p<.001$, see Figure 4 above). The duration of lenis stops is also significantly affected by context. Observe in Figure 4 that word-final pre-vocalic [z]-realisations-i.e. in the external sandhi voicing context-are significantly shorter than word-medial /z, 3/-realisations.

In contrast to the result for voicing ratio, differences in duration values extracted from sibilants produced by females and males are not strongly significant. Comparisons of duration values extracted from lenis sibilants do not reach significance for sex group, and sex-based differences in the duration of fortis sibilants reach only marginal significance $(p=0.036)$.

Analysis of word-medial sibilants reveals a small effect of stress context on sibilant duration: see Figure 5 below. However, comparisons of durational differences between post-tonic sibilants (as in casa [káze]) and pre-tonic sibilants (as in casal [kezáł]) do not reach significance $(p>.05)$. 


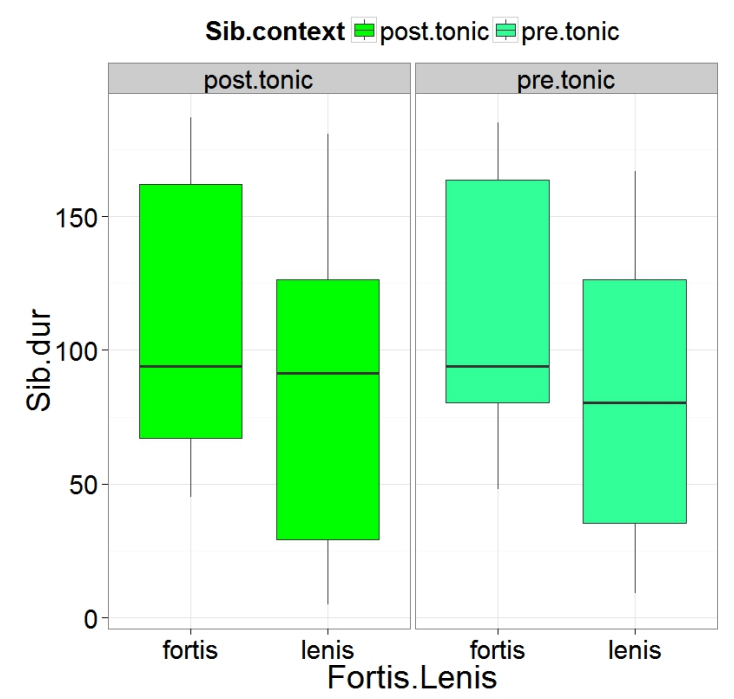

Figure 5: Duration of word-medial fortis and lenis sibilants: post-tonic vs pre-tonic stress conditions.

\subsubsection{Summary}

The phonetic experiment has confirmed, firstly, that fortis sibilants in EP are consistently produced without voicing. This has been observed both for female and male speakers. With regard to the lenis sibilants, we have observed that males produce / $\mathrm{z}, 3$ / with comparably high, but also very variable amounts of voicing. Females, by contrast, produce /z, 3/ with comparably low levels of voicing that is also characterised by high variability. Despite this difference in phonation between female and male speakers, a stable durational effect was observed: fortis sibilants are consistently longer than lenis sibilants for both sex groups. This effect is robust both for post-tonic and pre-tonic sibilants.

In $\S 3$ below, we address the implications of these results for phonological analysis of voicing in EP. Whilst our approach departs from conventional wisdom about the status of voicing contrasts in EP, it nevertheless invites us to ask interesting questions about possible diachronic developments that may underlie the synchronic data.

\section{Implications for synchronic analysis}

The results discussed above provide interesting insights into the status of synchronic voicing contrasts in EP. At first glance, it seems that the data are consistent with a traditional analysis of sibilant voicing based on binary [ \pm voice]. For example, the fact that the fortis sibilants, /s, $\mathrm{J} /$, never admit voicing can be accommodated under an analysis assuming 
that /s/ and / $/$ / are specified as [-voice]. Phonetic interpretation of [-voice] would entail generating a target for voicelessness, and speakers would realise this phonetic target through active devoicing (Jansen 2004): i.e. by actively performing a devoicing gesture that prevents vocal fold vibration. Conversely, if /z, $3 /$ are contrastively specified as [+voice], then we should expect to observe consistent acoustic correlates of active voicing in the realisation of these sounds. This is to say that phonetic implementation of [+voice] fricatives should involve articulatory exertion geared towards optimising aerodynamic conditions that maximally facilitate robust sibilant voicing. Whilst this is not what we have observed for EP-recall that voicing of /z, 3/ is variable both within and between sex groups - there are, nevertheless, stable durational differences between fortis and lenis sibilants. It is possible, therefore, that the phonological voicing contrast is signalled phonetically by long duration and consistent non-voicing (i.e. [-voice]) vs short duration and variable amounts of voicing (i.e. [+voice]).

By the same token, the data seem to present more of a challenge for laryngeal realism. Recall that Portuguese can be considered a true voice' language on the basis of its stop inventory: the relevant contrast is between a series of voiceless unaspirated stops, $/ \mathrm{p}, \mathrm{t}, \mathrm{k} /$, and a series of pre-voiceable stops, /b, d, g/ (Lousada et al. 2010). In the laryngeal realist tradition, this contrast is captured not by full feature specification, by rather through the opposition of a series of obstruents specified as [voice] with a series of obstruents underspecified for laryngeal features: see Figure 6 below.

\begin{tabular}{ccc}
\hline & Fortis & Lenis \\
& $\varnothing$ & {$[$ voice] } \\
\hline Stops & $/ \mathrm{p}, \mathrm{t}, \mathrm{k} /$ & $/ \mathrm{b}, \mathrm{d}, \mathrm{g} /$ \\
Fricatives & $/ \mathrm{f}, \mathrm{s}, \mathrm{J} /$ & $/ \mathrm{v}, \mathrm{z}, \mathrm{3} /$ \\
\hline
\end{tabular}

Figure 6: Obstruent inventory of EP (central standard dialect) assuming underspecification of fortis obstruents and [voice] specification of lenis obstruents.

This taxonomy entails a number of important phonetic predictions. Firstly, we expect that phonological specification for the feature [voice] should correspond to regular phonetic cues to obstruent voicing in lenis obstruents. Secondly the prediction for fortis obstruents is that the absence of phonological specification may lead to more variability in their phonetic realisation. The reason for this is that laryngeal realism relies directly on the notion of phonetic underspecification (Keating 1988, 1990a). That is, the representation of segments underspecified for laryngeal features need not be targets for feature filling processes throughout the derivation (cf. Mateus \& d'Andrade 2000: 37). Whilst 
this can happen-e.g. in cases of categorical assimilation by feature spread-it is not a requirement. Therefore, surface representations may contain laryngeally underspecified segments. Interpretation of such 'phonetically underspecified' segments is predicted to differ in theoretically non-trivial ways from interpretation of fully specified segments.

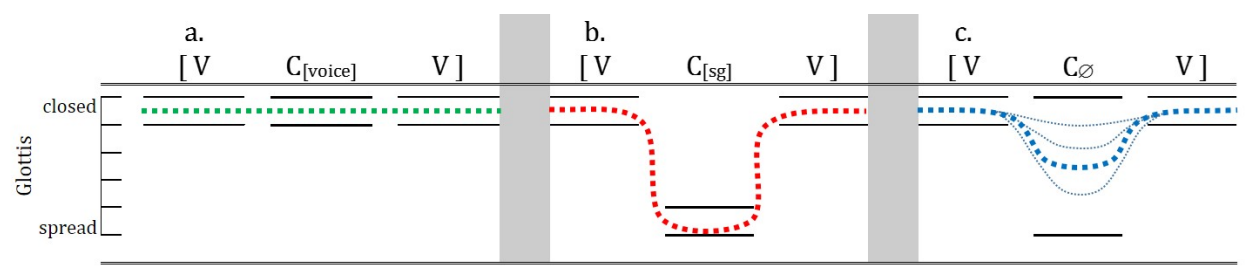

Figure 7: Phonetic implementation of [VCV] sequences in the window model. Solid horizontal bars represent targets for laryngeal constriction. Coloured dotted lines represent idealised contours of glottal aperture.

This idea can be straightforwardly visualised in Keating's (1990b) window model of co-articulation. As shown in Figure 7 above, implementation of a [VCV] sequence containing (a) a consonant phonologically specified for [voice] involves specifying a phonetic target for glottal adduction. This target takes the form of a narrow window: as shown, narrow window targets admit only minimal variation of the glottal aperture contour across the realisation of the [VCV] sequence. In (b), the intervocalic consonant is specified for [sg]. Here, note that the phonetic target for implementation of $\left[-\mathrm{C}_{\left.[\mathrm{sg}]^{-}\right]}\right.$is defined as a narrow window for vocal fold abduction (i.e. wide glottal opening). Realisation of this gestural plan therefore requires rapid opening and stiffening of the vocal folds in order to prevent any voicing of the intervocalic consonant. In between these two extremes is the realisation of sequence (c). The phonetically underspecified intervocalic consonant in this example receives a different laryngeal target in phonetic implementation: observe here that the $\left[-\mathrm{C}_{\circ}-\right]$ translates into a broad window spanning the full glottal aperture scale. As indicated by the alternative gestural trajectories (thin dotted lines), the consequence of this is that the realisation of $\left[-\mathrm{C}_{\varnothing}-\right]$ is predicted to admit much greater variation with respect to glottal aperture than either example (a) or example (b). Crucially, this does not necessarily mean that glottal opening will be uncontrolled in (c): evidence shows that individual speakers are very much in control of gradient phonetic gestures, and that controlled variation of the sort illustrated by the alternative aperture contours in (c) could reasonably represent conscious, stylespecific or socio-phonetic variation. Likewise, variation between 
gestural contours may be controlled to a greater or lesser extent on a language-specific basis. Nevertheless, one of the core ideas of this model of implementation is that phonetic underspecification presents the potential for greater phonetic variation than in the case of fully specified segments.

With regard to the EP data, the challenge is to accommodate the finding that lenis sibilants display highly variable levels of voicing into a phonological model assuming that lenis consonants are contrastively specified for [voice]. We must also account for the fact that putative underspecified fortis sibilants have a highly consistent, minimally variable realisation across all speakers.

In fact, the experimental data reveal that sibilants in EP display phonetic properties that contradict the predictions of the taxonomy given in Figure 6. Specifically, assuming that lenis fricatives are specified for [voice] in EP predicts a more stable homogeneity in the realisation of /z, 3/ than we have observed. Whilst the duration of the lenis sibilants is stable across phonological contexts and also consistently shorter than the fortis counterparts, it is important to highlight that realisations of / $\mathrm{z}, 3$ / in the current data bear hallmarks of passive, rather than active voicing. This is to say that whereas the durational correlates of the fortis vs lenis contrast are quite tightly controlled, speakers appear not to exercise the same level of control over voicing of /z, 3/. Some degree of vocal-fold vibration is observed in the realisation of the majority of lenis sibilants; ${ }^{6}$ yet their high variability-essentially varying from $0 \%$ voicing to $100 \%$ voicingcasts doubt upon the expectation that the implementation of lenis sibilants in EP involves the carefully controlled exertion of articulators necessary to achieve sustainable modal voicing of the type schematised in Figure 7(a). Conversely, what we have observed for /z, 3/ is more consistent with the implementation strategy shown in Figure 7(c): that is, that speakers permit lenis sibilants to be realised with vocal-fold vibration, but they do not actively maximise voicing in / $\mathrm{z}, 3 /$ to the fullest possible extent.

The fact that voicing of lenis sibilants is also significantly different for female and male speakers also ought not be overlooked. Previous research on voicing has indeed revealed patterns that are relevant for the current data. Koenig (2000: 1225) argues that women and men may employ different phonetic strategies to achieve consonant voicing, and that these strategies may, in turn, be different from those employed by children with immature articulatory systems. With regard to sibilants

\footnotetext{
${ }^{6}$ But not all: recall from Figure 2(a) that some realisations of /z/ or /3/ display a voicing ratio value of 0 in both sex groups.
} 
specifically, McLeod, Roberts \& Sita (2006) studied phonetic productions of /s/ and /z/ in ten adult speakers of English using EPG and found significant variability in the lingual constriction patterns involved in the articulation of these sounds, despite their shared phonological properties. In addition, various studies cite increased variability as evidence for passive voicing (e.g. Jansen 2004; Jessen 1998, 2004; Beckman et al. 2013); and similarly, higher levels of voicing are often observed for males, especially where voicing is passive (see Jessen 2009 for German and Nadeu \& Hualde 2015 on voicing of intervocalic /p, t, k/ in Spanish and Basque).

That EP lenis sibilants display characteristics of passive voicing has implications for phonological analysis. Given that the taxonomy in Figure 6 provides a relatively poor fit for the observed phonetic patterns, it is worth considering other ways in which the relevant contrasts may be analysed. Figure 8 below presents an alternative taxonomy for the EP obstruent inventory that departs both from traditional descriptions of the language based on binary [ \pm voice] and from the default laryngeal realist analysis for true voice languages. Here, the proposal is that EP may, in fact, instantiate what we term a hybrid voicing system: i.e. the relevant contrast feature is different in the stop series from the fricative series.

\begin{tabular}{ccc}
\hline & Fortis & Lenis \\
\hline \multirow{2}{*}{ Stops } & $\varnothing$ & {$[$ voice $]$} \\
& $/ \mathrm{p}, \mathrm{t}, \mathrm{k} /$ & $/ \mathrm{b}, \mathrm{d}, \mathrm{g} /$ \\
\multirow{2}{*}{ Fricatives } & {$[$ spread glottis] } & $\varnothing$ \\
& $/ \mathrm{f}, \mathrm{s}, \mathrm{S} /$ & $/ \mathrm{v}, \mathrm{z}, \mathrm{3} /$ \\
\hline
\end{tabular}

Figure 8: Alternative taxonomy for EP obstruents (central standard dialect).

Note that this conception of voicing contrasts makes no alteration to the analysis of the stop series given in Figure 6. As already stated, existing phonetic studies have demonstrated that although EP lenis stops sometimes display devoicing, they are pre-voiceable (i.e. they may display negative VOT) in certain contexts (Lousada et al. 2010). Likewise, fortis stops have not been shown to display the sort of aspiration expected of languages with [spread glottis] (henceforth [sg]) stops. We therefore take the view that a phonological analysis under which lenis /b, d, g/ are specified for [voice] and contrast with underspecified

/p, $\mathrm{t}, \mathrm{k} /$ makes adequate predictions about the phonetic realisation of these sounds. Work nevertheless remains to be done to understand 
the consequences of contextual lenis stop devoicing for phonological analysis of voicing contrasts and for speech perception.

The key proposal in Figure 8 has two elements: firstly, that it is not the fortis fricative series that is underspecified for laryngeal features, but rather the lenis series; and secondly, that the fortis series are contrastively specified for [spread glottis]. With regard to the phonetic implementation strategies illustrated in Figure 7, this alternative conception of the EP obstruent inventory crucially resolves two issues. The claim that fortis fricatives are [sg] predicts that their phonetic realisation should approximate the idealised gestural contour in Figure 6(b). This means that we should expect to observe rapid and consistent cessation of voicing in [VCV] sequences containing an intervocalic fortis sibilant as speakers implement active devoicing through carefully timed, controlled laryngeal gestures. Conversely, phonetic underspecification of lenis fricatives predicts an implementation strategy resembling Figure 6(c). Thus, because lenis sibilants do not bear a phonologically-defined feature that should regularly translate into a narrow phonetic target for a specific laryngeal configuration, we expect to observe greater variability in the phonetic realisation of /z, 3/ that is consistent with passive, rather than active voicing.

The predictions of Figure 8 therefore are a much closer match to the experimental results reported above than the more standard taxonomy shown in Figure 6, particularly with regard to voicing ratio measurements. One potential objection to this analysis, however, concerns the fact that the durational differences between fortis and lenis sibilants are relatively stable in our data. In other words, whilst variability in voicing is high in realisations of $/ \mathrm{z}, 3 /$ - as predicted by their phonetic underspecification for laryngeal features-durational variability is small. Why this may be remains an open question. A speculative explanation might be that durational stability arises as a compensation strategy for the fact that variable voicing reduces the perceptibility of contrast between [sg] sibilants and underspecified sibilants. In this sense, tighter durational control may enhance a contrast which is phonetically rather poorly cued by passive voicing alone. Alternatively, we might also entertain the possibility of a connection between phonological underspecification and relatively short duration. Further research will be necessary to clarify these issues.

Nevertheless, there are also typological factors worthy of mentioning if we accept the revised taxonomy in Figure 8. Beckman et al. $(2006,2009)$ have argued that German also displays a hybrid voicing system. On the basis of its stop realisations, German can be classified as an [sg] language: voiceless aspirated stops contrast with plain stops 
that are typically unvoiced in non-assimilation contexts. However, German also exhibits fricative voicing patterns that are not consistent with an analysis based on [sg] alone. Beckman et al. therefore propose that [voice] is employed as an additional contrast feature in the fricative series. ${ }^{7}$

\begin{tabular}{ccc}
\hline & Fortis & Lenis \\
\hline \multirow{2}{*}{ Stops } & {$[$ spread glottis] } & $\varnothing$ \\
& $/ \mathrm{p}, \mathrm{t}, \mathrm{k} /$ & $/ \mathrm{b}, \mathrm{d}, \mathrm{g} /$ \\
\multirow{2}{*}{ Fricatives } & {$[$ spread glottis] } & {$[$ voice] } \\
& $/ \mathrm{f}, \mathrm{s}, \int, \mathrm{x}, \mathrm{h} /$ & $/ \mathrm{v}, \mathrm{z} /$ \\
\hline
\end{tabular}

Figure 9: Taxonomy for German obstruents (adapted from Beckman et al. 2006, 2009).

What we are suggesting, therefore, is that EP is the typological mirror image of German, at least in part. As shown in Figure 9, the obstruent inventory of German contains sounds specified for [voice] and sounds specified for [sg], just as we propose for EP; yet it is the relative distribution of these features that differs between the two languages. Thus, if our analysis of EP is correct, then EP provides further evidence for existence of hybrid voicing systems crosslinguistically. In addition to making meaningfully different phonetic predictions from alternative approaches and potentially occupying a typological position that is the flipside counterpart of German, we might also ask whether hybrid voicing systems are universally available at all stages in a language's development, or whether they emerge diachronically. Given the fact that both German and EP are closely related to other languages in their respective language families that display different voicing patterns, it is not unreasonable to assume that hybrid voicing contrast is the product of historical phonological innovation. In the following sections, we consider some of the diachronic factors that, in the case of EP, may have led to the development of a hybrid voicing system.

\section{Historical changes affecting sibilants in Portuguese}

Much historical phonological research has provided evidence for the diachronic instability of sibilant fricatives; and in this, the IberoRomance languages generally, and EP specifically, are not exceptional.

\footnotetext{
7 The OT-based analysis presented in Beckman et al. $(2006,2009)$ assumes that fortis fricatives are [sg]-specified underlyingly in accordance with Lexicon Optimisation: see Beckman et al. (2009: 238) for relevant comments.
} 
Accordingly, it is appropriate to review briefly some of the changes that have shaped the sibilant system of EP historically.

Phonological studies on Classical Latin usually describe the language as having a single sibilant phoneme, /s/. The distribution of sibilants in present-day Romance Languages attests to the development of an allophonic process of intervocalic voicing (e.g. RosA /rosa/ $\rightarrow$ [roza] 'rose') at some point in the history of Latin. And it is from this process that Latin rhoticism subsequently developed, albeit irregularly (see Allen 1978: 35-37; Roberts 2012).

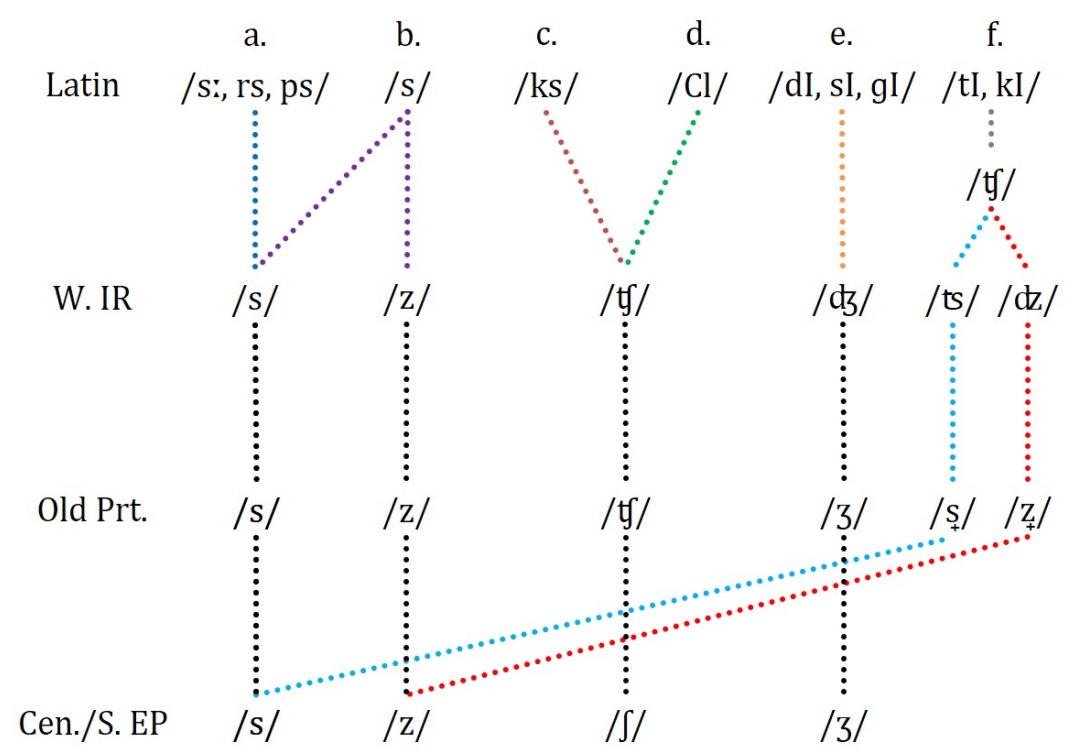

Figure 10: Development of sibilants in central standard EP from Latin via Western Ibero-Romance and Old Portuguese.

With regard to Ibero-Romance, a complex series of phonological changes ultimately resulted in the emergence of multiple sibilant phonemes (see Figure 10). The development shown in (a-b) is a case of secondary split: whereas Latin exhibited $/ \mathrm{s} / \rightarrow[\mathrm{z}]$ intervocalically, intervocalic singleton [s] emerged from cases of degemination and cluster simplification (e.g. MASSA /masia/ > /masa/ 'dough'). This change rendered the distribution of $[\mathrm{s}]$ and $[\mathrm{z}]$ unpredictable. The Latin allophonic pattern that mapped /s/ to [s] or [z] context-dependently was therefore reanalysed as a phonemic distinction. Instances of Latin /s/ that did not display contextual voicing merged with instances of /s/ that arose from simplification by change (a), whereas instances of Latin /s/ in (b) that were contextually voiceable to [z] were reanalysed as mappings of phonemic /z/. 
Palatalisation is the second source of sibilant fricatives in Portuguese. Some instances of (c) Latin / ks/ and (d) certain muta cum liquida sequences merged into a palatal/post-alveolar affricate. Instances of $/ \mathrm{t} /$ derived from Latin $/ \mathrm{Cl} /$-clusters ultimately underwent de-affrication in central and southern dialects of EP, thereby yielding /S/: e.g. FLAMA > / tama/ > / ama/ 'flame'; PLICARE > / tegar / > / egar / 'arrive'. Instances of $/ \mathrm{ksI} /$ show evidence of palatalisation and metathesis: e.g. AXIS > /ejfu/ 'axle' (see Wireback 1997: §2).

Sequences of voiced consonant + yod (e) palatalised to /3/ via an intermittent stage of affrication: e.g. FUGIO > /fudzo/ > /fuzu/ 'flee.1SG'. Intervocalic /sI/ is also a source of /3/ through voicing, palatalisation and metathesis: e.g. CASEUM $(>/ \mathrm{kazi}-/)>/$ kejzu/ 'cheese'. As shown in (f) sequences of $/ \mathrm{t} /+$ yod and $/ \mathrm{k} /+$ yod underwent palatalisation to $/ \mathrm{t} /$; yet crucially, these instances of $/ \mathrm{t} /$ did not merge with those generated through changes (c-d). Instead / $\mathrm{t} /$ from /tI/ and / kI/ underwent fronting and deaffrication: e.g. CAPTIARE $>/$ katfar $>/$ katsar $/>/$ kașar $/$ 'capture, hunt'; ERICIUS > /oritso/ > /orișu/ 'hedgehog'. Some items display, somewhat sporadically, intervocalic voicing in addition to affrication and fronting: e.g. PRETIARE > /preckar/ > /prezar/ 'value'; ACIDUS $>$ /adzedo/ > /azedu/ 'sour'. Central and southern dialects of EP are then characterised by the merger of (f) /ș $\mathrm{z} /$ derived from Latin /tI/ and /kI/ with (a-b) /s, z/ derived from Latin /s/, /s:/ and /Cs/clusters: hence, /kasar/, /orisu/; /prezar/, /azedu/. ${ }^{8}$

The cumulative effect of these changes was the emergence of six separate sibilant phonemes (at the maximal stage) in the history of Portuguese. Such dramatic change clearly went hand-in-hand with a restructuring of the laryngeal system; and consideration of the mechanisms behind these changes is relevant for developing a theoretical account of how a synchronic hybrid voicing contrast may have arisen historically in EP.

It seems reasonable to assume that Latin-in both classical and vulgar varieties-was a true voice language. One important piece of evidence for this is that existing studies on present-day daughter languages describe lenis stops as fully voiceable: for example, see Recasens (1996: 41-43) on Catalan, Caramazza \& Yeni-Komshian (1974) on French, Casteñada Vicente (1986) on Spanish, Esposito

\footnotetext{
8 Note that this merger did not occur elsewhere: some northern dialects of EP preserve the 6-way contrast exemplified by Old Portuguese. In other northern dialects, the outcome of merger is different: /s/ and /z/ are lost whereas /s/ and /z/ remain preserved (see Teyssier 1982: 48-56; Mateus \& d'Andrade 2000: 13-14). See also Carvalho (2011) for discussion of textual evidence for the gradual merger of /s/ with /s/ and /z/ with /z/; and see Widdison (1987) and Penny (2002) for relevant observations on the (rather different) outcome of these changes in Spanish.
} 
(2002) and Hualde \& Nadeu (2011) on Italian. Under the assumption that Latin was a true voice language, its obstruent inventory can be reconstructed as in Figure 11 below. Note here that whilst Latin contrasts fortis and lenis stops, there are only fortis fricatives: the inventory does not contain a series of lenis fricatives.

\begin{tabular}{ccc}
\hline & Fortis & Lenis \\
& $\varnothing$ & [voice] \\
\hline Stops & $/ \mathrm{p}, \mathrm{t}, \mathrm{k} /$ & $/ \mathrm{b}, \mathrm{d}, \mathrm{g} /$ \\
Fricatives & $/ \mathrm{f}, \mathrm{s}, \mathrm{h} /$ & - \\
\hline
\end{tabular}

Figure 11: Obstruent inventory of Latin.

An important consequence of the historical changes outlined above is the population of this empty cell. If we assume that /z, 3/ (and also $/ \mathrm{v} /$ ) were added to the existing inventory, then the result for early Portuguese is the voicing system shown in Figure 6. Yet as discussed, this taxonomy is not a good fit to phonetic data from present-day Portuguese. This brings us to a final question: if our reanalysis of the synchronic EP sibilant inventory based on [sg] is correct, how has a hybrid voicing system developed over time from a system in which lenis fricatives were presumably once [voice]-specified?

\section{Development of hybrid voicing contrast}

We hypothesise that the key to this question lies in a cross-linguistic preference for fricatives to be voiceless. On the basis of a survey of a number of unrelated languages, Vaux (1998) makes two important claims with regard to hybrid voicing contrast. Firstly, Vaux argues that the cross-linguistically most common obstruent system-i.e. the least marked one-is one in which voiceless fricatives are [sg]-specified. ${ }^{9}$ Secondly, laryngeal contrasts in fricatives need not parallel contrasts in stops: thus, '[t]he laryngeal specifications of the fricatives [...] cannot be derived from the structure of the stop inventory' (Vaux 1998: 508).

The first point has a clear phonetic basis. A speech-production target for fricative voicelessness can only be achieved through some degree of vocal fold abduction (Stevens 1998: 379-384). This is the observation underlying Jansen's (2004) active devoicing: i.e. that robust voicelessness is achieved through carefully controlled articulatory configurations. Vaux (1998), along with other phonologists, suggests

9 More specifically, Vaux assumes a binary [ $\pm \mathrm{sg}]$ feature. Therefore, voiceless fricatives are argued to be [+sg] in an unmarked voicing system. 
that this phonetic generalisation is the source of a UG-encoded phonological bias towards [sg]-specification on voiceless fricatives. For example, van Oostendorp (2007: 88-91) and Beckman et al. (2006: 82, 2009: 237) make use of an OT constraint requiring that fricatives should be [sg]-specified on the surface in their analyses of Dutch and German, respectively. This approach therefore relates voicing patterns in these languages to the hierarchical ranking of a phoneticallygrounded constraint that specifically penalises phonological voicing of fricatives. That such a constraint is both rankable and violable also means that its effects may be counteracted by other, superordinate constraints in languages that display cross-linguistically rarer voicing patterns (in this connection, Vaux 1998: 508 mentions Burmese and Chinese).

With regard to the second point, the lack of implicational predictability between the laryngeal phonology of stops and that of fricatives aligns with the analysis of German proposed by Beckman et al. and with our analysis of EP. Although some true voice languages have symmetrical systems-i.e. contrasting [voice]-specified lenis stops and fricatives with fortis stops and fricatives that are underspecified for laryngeal features-as do some spread glottis languages-i.e. contrasting [sg]-specified fortis obstruents with underspecified lenis obstruents - this type of symmetry is not required. Hybrid voicing systems are entirely consistent with Vaux's observations about crosslinguistic preference for fricative voicelessness.

In this connection, Iverson \& Salmons (2003: 14-15) argue that the preference for [sg]-specified voiceless fricatives can manifest itself allophonically in true voice languages (i.e. Glottal Tension systems, in their terminology). Recall that in a laryngeal realist approach, fortis obstruents are underspecified for laryngeal features in true voice systems (as in Figure 6). However, in line with the observation that glottal abduction is necessary for the production of fricative voicelessness, Iverson \& Salmons argue that [sg] may be assigned by a redundancy rule to lexically underspecified fortis fricatives as a phonetic enhancement strategy. This rule has the effect of phonologically programming phonetic implementation to maximise voicelessness in fricative articulations along the lines of Figure 7(b). Whether the predictions of this analysis match the phonetic voicing patterns of all true voice languages awaits confirmation from experimental study. Nevertheless, Iverson \& Salmons' proposal has interesting implications for developing a theoretical account of the emergence of hybrid voicing contrast in EP.

Figure 12 below presents a hypothetical reconstruction of diachronic changes affecting the laryngeal system of EP. At the initial 
stage, which we refer to here as Proto-EP 1, lenis obstruents are contrastively specified for [voice], whereas fortis obstruents are lexically underspecified for laryngeal features. Accordingly, Proto-EP 1 reflects the historical situation after the development of voicing contrast in fricatives in Western Ibero-Romance (see Figure 10). The reconstruction also incorporates Iverson \& Salmons' claim that [sg] can be assigned by default to underspecified fortis fricatives as a phonological strategy to enhance phonetic voicelessness. Crucially, this occurs only in fortis fricatives, not in fortis stops: fortis stops are implemented with a target for short-lag positive VOT (i.e. without aspiration).

(a)

\begin{tabular}{|c|c|c|}
\hline \multicolumn{2}{|c|}{ Proto-EP 1: } & \\
\hline & fortis & lenis \\
\hline stops & $\varnothing$ & [voice] \\
\hline fricat. & $\varnothing$ & [voice] \\
\hline
\end{tabular}

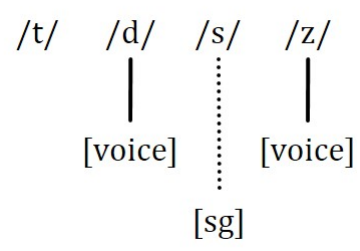

(b)

\begin{tabular}{|c|c|c|}
\hline \multicolumn{2}{|c|}{ Proto-EP 2: } & \\
\hline & fortis & lenis \\
\hline stops & $\varnothing$ & [voice] \\
\hline fricat. & {$[\mathrm{sg}]$} & [voice] \\
\hline
\end{tabular}

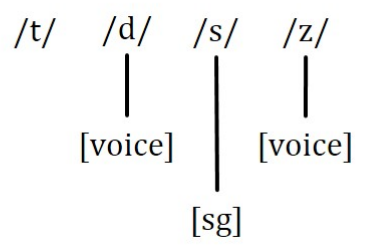

(c)

\begin{tabular}{|c|c|c|c|}
\hline \multicolumn{2}{|c|}{ Pres. day EP: } & & \multirow{3}{*}{$\left.\right|_{\text {[voice] }} ^{\mathrm{t} /}$} \\
\hline & fortis & lenis & \\
\hline stops & $\varnothing$ & [voice] & \\
\hline fricat. & {$[\mathrm{sg}]$} & $\varnothing$ & [sg \\
\hline
\end{tabular}

Figure 12: Development of hybrid voicing contrast in EP.

The next phase, shown in Figure 12(b), represents EP after a further phase of historical change. Whereas surface [sg]-specification on fortis fricatives is the result of a derivational process in Proto-EP 1i.e. through default epenthesis of $[\mathrm{sg}]-[\mathrm{sg}]$ is present lexically in the representation of fortis fricatives in Proto-EP 2. In other words, [sg] is not supplied to fortis fricatives by default specification at the synchronic stage of Proto-EP 2; but rather all fortis fricatives have become contrastively specified for [sg]. Our proposal is therefore that 
the derivational process that was once active in the phonology of ProtoEP 1 has undergone reanalysis historically in Proto-EP 2.

A reasonable question to ask at this point is what the mechanism underlying the change between Proto-EP 1 and Proto-EP 2 may have been. Crucially, note that the surface phonology of Proto-EP 1 and Proto-EP 2 is identical with regard to laryngeal features: all lenis obstruents are [voice]-specified, fortis fricatives are [sg]-specified, but fortis stops remain phonetically underspecified. This also means that the input to phonetic implementation is the same at the two stages. However, what differs between proto stages 1 and 2 is the source of the [sg] surface feature. If we assume that, other things being equal, [sg]insertion was a regular and exceptionless process in Proto-EP 1, speakers of this dialect later on down the generational line may associate the presence of [sg] on fortis fricatives at surface level, not with a default feature assignment rule, but rather with lexical specification. Thus, Proto-EP 2 represents a historical stage in the language after the deactivation of the Iverson and Salmons' fortis fricative enhancement rule and the construction of lexical forms in which fortis fricatives are [sg]-specified.

Yet if this hypothesis is correct, observe that lexicalisation of [sg] on fortis fricatives goes hand-in-hand with an increase in redundancy. This is to say that at the synchronic stage of Proto-EP 2, laryngeal contrasts in the fricative series are overspecified. The final stage in the reconstruction of the development of the hybrid voicing system we propose for present-day EP-i.e. (c) in Figure 12-comes about through loss of [voice]-specification on lenis fricatives. This, in turn, eliminates the overspecification present synchronically in the obstruent phonology of Proto-EP 2. Although this historical stage is hypothetical, we might speculate that the cause of such a development lies in acquisition. If we accept the argument that the phonetic challenges of producing fricative voicing may manifest themselves grammatically in the form of a constraint favouring fricative voicelessness (i.e. as in Beckman et al. 2006, 2009; van Oostendorp 2007), then we might also reasonably hypothesise that child learners of language are in some way predisposed to construct phonological grammars that militate against such marked structures, at least up to a certain developmental stage. Consistent with this scenario is the further hypothesis that children may tune into the robust voicelessness of fortis fricatives as being a major cue for the fortis lenis contrast in fricatives early on in phonological acquisition. ${ }^{10}$ This being the case, children exposed to

10 The typical longer duration of fortis fricatives relative to the typical shorter duration of lenis fricatives may also play a role here. 
Proto-EP 2 may successfully associate voicelessness with [sg] for fortis fricative. Yet given that no additional feature is required for expression of the fortis lenis contrast in fricatives, it is also conceivable that child learners may fail to make a link between lenis fricative voicing and the contrastive [voice] feature that characterises the overspecified parent inventory. The result of this developmental trajectory would be the simplification of the Proto-EP 2 obstruent system to that of Figure 12(c).

Simplification of the laryngeal phonology of Proto-EP 2 therefore has the effect of replacing a series of [voice]-specified lenis fricatives with a series of fricatives underspecified for laryngeal features. As already discussed, if we assume that underspecified fricatives are not targets for any sort of phonological feature-filling process (except in CCassimilation contexts), then we predict a phonetic implementation strategy for lenis fricatives in present-day EP that differs both from Proto-EP 2 and from other true voice languages in which lenis fricatives are [voice]-specified. Thus, whereas the realisation of lenis fricatives in other Romance varieties may bear closer resemblance to the implementation pattern illustrated in Figure 7(a), /z, 3/ (and also /v/) in present-day EP are predicted to exhibit variable passive voicing precisely because they are phonetically underspecified for laryngeal features synchronically.

In sum, whilst the analysis we propose for present-day EP on the basis of phonetic study of voicing in sibilants involves taking a rather large step away from traditional phonological descriptions of the language, we see two main advantages in our approach. Firstly, proposing that present-day EP has a hybrid voicing system makes phonetic predictions that are a much better fit with existing data (at least for the central standard dialect). Secondly, our synchronic analysis fits in with a broader diachronic picture: in this sense, we view hybrid voicing contrast in EP as the outcome of a series of inter-related historical changes. To use Iverson \& Salmons' term, [voice]specification in lenis stops is a 'legacy feature' that EP has inherited from Latin. By contrast, [sg]-specification in fortis fricatives has arisen diachronically as the cumulative result of (i) the historical development of new contrasts in the obstruent system, (ii) cross-linguistic pressure for lenis fricatives to be unvoiced, and (iii) the generation and (iv) subsequent elimination of overspecification in the laryngeal system of the language. 


\section{Conclusion}

Under the assumption that European Portuguese should display phonological patterns similar to those found in closely related Romance languages, laryngeal contrast in obstruents has typically been conceptualised as an opposition of [+voice] and [-voice]. However, this type of approach is at odds with observations from experimental phonetic studies on voicing. In particular, voicing in putative voiced fricatives in EP has been shown to be irregular and, in Pape \& Jesus's (2011) view, 'more similar to a Germanic language than to other Romance languages'.

In this paper, we have argued for an alternative phonological approach to laryngeal contrast in EP that is based on detailed phonetic study of voicing in sibilants. Rather than assuming a strict parallelism with regard to contrasts in the stop and fricative series, we have proposed that EP exemplifies a hybrid voicing contrast. Thus, whereas EP contrasts [voice]-specified lenis stops with laryngeally underspecified fortis stops, our claim is that [voice] is not the key contrast feature for fricatives in the language. On the contrary, we have presented arguments in favour of considering [spread glottis] as the relevant contrast feature in fricatives. Our claim that EP contrasts [sg]specified fortis fricatives with laryngeally underspecified lenis fricatives allows us to make specific predictions about the implementation of voicing contrast which are a close fit to our experimental results.

Furthermore, we have shown that our proposals about laryngeal contrast in present-day EP can be accommodated into a theoretical framework that may offer an explanation of how hybrid voicing contrast develops over time. In the case of EP, we have argued that hybrid voicing contrast has resulted, firstly, from a series of phonological changes that caused a remodelling of the obstruent inventory of Western Ibero-Romance. Secondly, phonetic and phonological pressures for maximal voicelessness in the realisation of fortis fricatives (Vaux 1998; Iverson \& Salmons 2003) ultimately led to activation of [sg] in a [voice]-based laryngeal system. Thirdly, a side effect of lexicalisation of [sg]-specification on fortis fricatives is the generation of overspecification in the obstruent inventory. We have argued, fourthly, that [voice] is ultimately eliminated as a contrast feature in the fricative series as phonetic preference for fricative voicelessness exerts an influence on phonological acquisition. The loss of [voice]-specification on lenis fricatives is the final stage in the development of the hybrid voicing system in present-day EP. Thus, although our analysis of the laryngeal phonology of EP is perhaps not the most obvious from a strictly synchronic perspective, the advantage of our approach is that it ties experimental phonetic observations 
together with both synchronic and diachronic theoretical phonological claims.

\section{Comments invited}

PiHPh relies on post-publication review of the papers that it publishes. If you have any comments on this piece, please add them to its comments site. You are encouraged to consult this site after reading the paper, as there may be comments from other readers there, and replies from the author. This paper's site is here:

http://dx.doi.org/10.2218/pihph.1.2016.1704

\section{Acknowledgements}

We wish to thank members of the Phonetics Laboratory at the University of Lisbon, in particular Sónia Frota, Marisa Cruz and Joe Butler, for their invaluable help in recruiting speakers for this study and for granting access to their lab for recording. We received many useful comments from audiences at $\mathrm{mfm} 23$ and the Second Edinburgh Symposium on Historical Phonology, for which we are also very grateful. Comments on a previous draft of this paper from Ricardo Bermzúdez-Otero and Patrick Honeybone were also very useful and gratefully received. Any remaining errors are our own.

\section{Author contact details}

Michael Ramsammy

School of Philosophy, Psychology and Language Sciences

University of Edinburgh

Dugald Stewart Building

3 Charles Street

Edinburgh. EH8 9AD.

m.ramsammy@ed.ac.uk

Patrycja Strycharczuk

School of Arts, Languages and Cultures

University of Manchester

Oxford Road

Manchester. M13 9PL.

patrycja.strycharczuk@manchester.ac.uk 


\section{References}

Allen, W. Sidney. 1978. Vox Latina: the pronunciation of Classical Latin ( $2^{\text {nd }}$ ed.). Cambridge: Cambridge University Press.

Azevedo, Milton M. 2005. Portuguese: a linguistic introduction. Cambridge: Cambridge University Press.

Beckman, Jill, Michael Jessen \& Catherine Ringen. 2006. Phonetic variation and phonological theory: German fricative voicing. Proceedings of the $25^{\text {th }}$ West Coast Conference on Formal Linguistics: 76-86.

Beckman, Jill, Michael Jessen \& Catherine Ringen. 2009. German fricatives: coda devoicing or positional faithfulness? Phonology 26/2: 231-268.

Beckman, Jill, Michael Jessen \& Catherine Ringen. 2013. Empirical evidence for laryngeal features: aspirating vs true voice languages. Journal of Linguistics 49/2: 259-284.

Boersma, Paul \& David Weenink. 1992-2016. Praat: doing phonetics by computer.

Caramazza, A. \& G. H. Yeni-Komshian. 1974. Voice onset time in two French dialects. Journal of Phonetics 2: 239-245.

Carvalho, Maria José. 2010. Duas inovações consonânticas num corpus medieval: simplificação do sistema de quatro sibilantes e neutralização da oposição fonológica b/v. In Armanda Costa, Isabel Falé \& Pilar Barbosa (eds) Textos selecionados do XXVI Encontro Nacional da Associação Portuguesa de Linguística. Lisbon: Associação Portuguesa de Linguística.

http://www.apl.org.pt/apl-actas/xxvi-encontro-nacional-daassociacao-portuguesa-de-linguistica.html.

Casteñada Vicente, María L. 1986. El V.O.T. de las oclusivas sordas y sonoras españolas. Estudios de fonética experimental 2: 93-110.

Esposito, Anna. 2002. On vowel height and consonantal voicing effects: data from Italian. Phonetica 59: 197-231.

Hammarström, Göran. 1953. Étude de phonétique auditive sur les parlers de l'Algarve. Uppsala: Almqvist \& Wiksells Boktryckeri AB.

Herslund, Michael. 1986. Portuguese sandhi phenomena. In Henning Andersen (ed.) Sandhi phenomena in the languages of Europe. Berlin: Mouton de Gruyter, 505-218.

Honeybone, Patrick. 2005. Diachronic evidence in segmental phonology: the case of obstruent laryngeal specifications. In Marc van Oostendorp and Jeroen van de Weijer (eds) The internal organization of phonological segments. Berlin: Mouton de Gruyter, 319-354.

Hualde, José Ignacio \& Marianna Nadeu. 2011. Lenition and phonemic overlap in Rome Italian. Phonetica 68: 215-242. 
Iverson, Gregory K. \& Joseph C. Salmons. 1995. Aspiration and laryngeal representation in Germanic. Phonology 12: 369-396.

Iverson, Gregory K. \& Joseph C. Salmons. 2003. Legacy specification in the laryngeal phonology of Dutch. Journal of Germanic Linguistics 15/1: 1-26.

Iverson, Gregory K. \& Joseph C. Salmons. 2006. On the typology of final laryngeal neutralization: Evolutionary Phonology and laryngeal realism. Theoretical Linguistics 32/2: 205-216.

Jansen, Wouter. 2004. Laryngeal contrast and phonetic voicing: a laboratory phonology approach to English, Hungarian and Dutch. $\mathrm{PhD}$ thesis, University of Groningen.

Jessen, Michael. 1998. Phonetics and phonology of tense and lax obstruents in German. Amsterdam: John Benjamins.

Jessen, Michael. 2004. Instability in the production and perception of intervocalic closure voicing as a cue to $b d g$ vs $p t k$ in German. Folia Linguistica 38/1-2: 27-42.

Jesus, Luis M. T. \& Christine H. Shadle. 2002. A parametric study of the spectral characteristics of European Portuguese fricatives. Journal of Phonetics 30: 437-464.

Hothorn, Torsten, Kurt Hornick, Carolin Strobl, Achim Zeileis. 2015. party: a laboratory for recursive partitioning (R package).

Keating, Patricia A. 1988. Underspecification in phonetics. Phonology 5: 275-292.

Keating, Patricia A. 1990a. Phonetic representations in generative grammar. Journal of Phonetics 18: 321-334.

Keating, Patricia A. 1990b. The window model of coarticulation: articulatory evidence. In John Kingston \& Mary Beckman (eds.) Papers in Laboratory Phonology I. Cambridge: Cambridge University Press, 451-70.

Koenig, Laura L. 2000. Laryngeal factors in voiceless consonant production in men, women and 5-year-olds. Journal of Speech, Language and Hearing Research 43: 1211-1228.

Lousada, Marisa, Luis M. T. Jesus and Andreia Hall. 2010. Temporal acoustic correlates of the voicing contrast in European Portuguese. Journal of the International Phonetic Association 40/3: 261-275.

McLeod, Sharynne, Amber Roberts \& Jodi Sita. 2006. Tongue/palate contact for the production of /s/ and /z/. Clinical Linguistics \& Phonetics 20/1: 51-66.

Nadeu, Marianna \& José Ignacio Hualde. 2015. Biomechanically conditioned variation at the origin of diachronic intervocalic voicing. Language and Speech 58/3: 351-370. 
Oostendorp, Marc van. 2007. Exceptions to final devoicing. In Jeroen van de Weijer \& Erik Jan van der Torre (eds) Voicing in Dutch: (De)voicing-phonology, phonetics and psycholinguistics. Amsterdam: John Benjamins.

Pape, Daniel \& Luis M. T. Jesus. 2011. Devoicing of phonologically voiced obstruents: is European Portuguese different from other Romance Languages? Proceedings of ICPhS 17: 1566-1569. https://www.internationalphoneticassociation.org/icphsproceedings/ICPhS2011/OnlineProceedings/RegularSession/Pap e/Pape.pdf

Pape, Daniel \& Luis M. T. Jesus. 2015. Stop and fricative devoicing in European Portuguese, Italian and German. Language and Speech 58/2: 224-246.

Peirce, Jonathan W. 2007. PsychoPy: Psychophysics software in Python. Journal of Neuroscience Methods 162/1-2: 8-13.

Penny, Ralph. 2002. A history of the Spanish language. Cambridge: Cambridge University Press.

Pinho, Cátia M. R., Luis M. T. Jesus \& Anna Barney. 2012. Weak voicing in fricative production. Journal of Phonetics 40: 625-638.

Plug, Leendert \& Paul Carter. 2013. Prosodic marking, pitch and intensity in spontaneous lexical self-repair in Dutch. Phonetica 70/3: 155-181.

R core team. 2016. R: A language and environment for statistical computing. R Foundation for Statistical Computing.

Ramsammy, Michael \& Patrycja Strycharczuk. In preparation. Sibilant voicing in European Portuguese.

Recasens, Daniel. 1996. Fonètica descriptiva del català: assaig de caracterizació de la pronúncia del vocalisme i consonantisme del català al segle XX. Barcelona: Institut d'Estudis Catalans.

Roberts, Philip J. 2012. Latin rhotacism: a case study in the life cycle of phonological processes. Transactions of the Philological Society 110/1: 80-93.

Stevens, Kenneth N. 1998. Acoustic phonetics. Cambridge Massachusetts: MIT Press.

Strycharczuk, Patrycja. 2012. Phonetics-phonology interactions in presonorant voicing. $\mathrm{PhD}$ thesis, University of Manchester.

Strycharczuk, Patrycja, Marijn van 'T Veer, Martine Bruil \& Kathrin Linke. 2014. Phonetic evidence on phonology-morphosyntax interactions: sibilant voicing in Quito Spanish. Journal of Linguistics 50: 403-452.

Tagliamonte, Sali A. \& Harald Baayen. 2012. Models, forests and trees of York English: was/were variation as a case study for statistical practice. Language Variation and Change 24/2: 135-178. 
Teyssier, Paul. 1982. História da língua portuguesa. Lisbon: Sá da Costa Editora.

Vaux, Bert. 1998. The laryngeal specifications of fricatives. Linguistic Inquiry 29/3: 497-511.

Widdison, Kirk A. 1987. $16^{\text {th }}$ century Spanish sibilant reordering: reasons for divergence. Proceedings of the Deseret Language and Linguistics Society Symposium 13/1: 63-70. http://scholarsarchive.byu.edu/dlls/vol13/iss1/9/

Wireback, Kenneth. 1997. The role of phonological structure in sound change from Latin to Spanish and Portuguese. New York: Peter Lang. 